\title{
Uptake and release of free L-carnitine by boar epididymal spermatozoa in vitro and subsequent acetylation rate
}

\author{
C. Jeulin ${ }^{1}$, J. L. Dacheux ${ }^{2}$ and J. C. Soufir ${ }^{1}$ \\ ${ }^{1}$ Biologie Cellulaire et Biologie de la Reproduction et du Développement, CHU, \\ 94275 Le Kremlin-bicêtre Cedex, France; and '2Station de Physiologie de la Reproduction, INRA, \\ 37380 Nouzilly, France
}

\begin{abstract}
In the male reproductive tract, very high concentrations $\left(\mathrm{mmol} \mathrm{l}^{-1}\right)$ of free $\mathrm{L}$-carnitine and acetyl-L-carnitine are found in the epididymides, seminal plasma and spermatozoa. It has been reported that the uptake of free L-carnitine by spermatozoa might be related to the epididymal maturation of the sperm membrane, since a greater uptake was found by caput than by cauda spermatozoa in vitro. However, the free L-carnitine concentrations estimated inside the gametes were never greater than those of the surrounding medium. In this study, we investigated the mechanism of transport of free L-carnitine and its ester acetyl-L-carnitine, through the plasma membrane of mature and immature epididymal boar spermatozoa. In vitro, we found a passive diffusion of both compounds to the spermatozoa, whatever the maturation stage. The spermatozoa might progress in the epididymal lumen and accumulate high amounts of free L-carnitine. The active uptake of free L-carnitine occurs only across epididymal mucosa. These results are in agreement with those reported on cells of other organs that exchange pharmacological free L-carnitine concentrations (mmol $\mathrm{I}^{-1}$ ) by a passive mechanism through the plasma membrane. The acetylation of high amounts of free L-carnitine inside the spermatozoa was found only in caudal spermatozoa. This result suggests that oxidative metabolism (producing acetyl $\mathrm{CoA}$ ) might be more active in mature cells. The acetyl-L-carnitine added to the incubation medium of boar spermatozoa was hydrolysed. Enzymatic activity of the sperm membrane is low and this may partially explain the low concentrations of acetyl-L-carnitine found in the caudal epididymal plasma.
\end{abstract}

\section{Introduction}

Free L-carnitine ( $\beta$-hydroxy- $\gamma-N$-trimethylaminobutyric acid) is an essential cofactor in mitochondrial transport and oxidation of fatty acids (Bremer, 1983). Free L-carnitine and its short (acetyl-L-carnitine), medium and long chain acyl esters are members of the carnitine family. Free L-carnitine is synthesized in several tissues (liver, kidney and brain) and is absorbed from dietary sources. The concentration of free L-carnitine in the blood plasma is approximately $10-50 \mu \mathrm{mol}^{-1}$ in rats (Hinton and Setchell, 1980; Marciani et al., 1991) and humans (Li et al., 1992).

At physiological concentrations $\left(\mu \mathrm{mol} \mathrm{I}^{-1}\right)$ in the blood plasma, free L-carnitine is absorbed through an active and specific transport process in tissues that depend on fatty acid oxidation, for example skeletal and cardiac muscle (Bohmer et al., 1977; Rebouche, 1977). Total carnitine uptake (free L-carnitine, acetyl-L-carnitine and acyl-L-carnitine) has been studied in several tissues in culture, in vivo or in isolated organs, and the different effects of physiological $\left(\mu \mathrm{mol} 1^{-1}\right)$ or pharmacological (mmol l${ }^{-1}$ ) concentrations have been reported by Li et al. (1992). Kinetic parameters of physiological

Received 13 May 1993. concentrations of free L-carnitine differ considerably among the various tissues and depend on tissue-specific processes. An ionic regulation of active transport of carnitine was also reported by Borum (1983).

In the male reproductive tract, free L-carnitine concentration is especially high (of the order of mmol $\mathrm{l}^{-1}$ ) in the epididymides (Casillas, 1972), seminal plasma (Marquis and Fritz, 1965) and spermatozoa (Brooks, 1980). The accumulation of free L-carnitine in the epididymal lumen is androgen dependent and a specific carrier occurs in rats (Yeung et al., 1980; Hinton and Setchell, 1980; Cooper et al., 1986a) and monkeys (Cooper et al., 1986b). A 2000-fold difference between the free L-carnitine concentration in the blood $\left(\mu \mathrm{mol} \mathrm{I}{ }^{-1}\right)$ and the epididymal fluid ( $\mathrm{mmol} \mathrm{l}^{-1}$ ) was reported in rats and boars (Brooks, 1979a,b; Hinton et al., 1979). The concentration of free L-carnitine in the spermatozoa of bulls, rabbits, hamsters, rams and boars increased as they pass down the epididymal duct (Casillas, 1973; Casillas and Chaipayungpan, 1979; Inskeep and Hammerstedt, 1982; Casillas et al., 1984; Jeulin et al., 1987). However, contradictory data were reported about uptake of free L-carnitine and acetyl-L-carnitine by the epididymal spermatozoa. In bulls, Casillas (1973) and Day-Francesconi and Casillas (1982) found that the uptake of free L-carnitine is related to epididymal maturation and greater for caput 
spermatozoa than for cauda cells. However, the intracellular concentration of free L-carnitine in the gametes was never greater than that of the surrounding medium (Jeulin et al., 1987). The passage of free L-carnitine through the sperm plasma membrane has not been shown and an active transport mechanism has not been demonstrated.

In spermatozoa, as in most tissues and cells, some of the $\mathrm{L}$-carnitine is acetylated. The concentration of acetyl-L-carnitine in the epididymal spermatozoa is variable according to the species and location of the epididymal regions. The intracellular concentration of this compound during the sperm maturation process is stable in hamsters (Casillas et al., 1984), whereas it increases in rams and boars (Inskeep and Hammerstedt, 1982; Jeulin et al., 1987). High concentrations of acetyl-L-carnitine (>20 mmol l-1) were reported in cauda spermatozoa from bulls and boars (Van Dop et al., 1977; Jeulin et al., 1987). The origin of acetyl-L-carnitine inside epididymal spermatozoa is not well established. In bovine and monkey spermatozoa, the intracellular free L-carnitine is acetylated during incubation with glucose and de-acetylated in its absence (Casillas and Erickson, 1975). In hypotonically demembranated mature spermatozoa, free L-carnitine is taken up into the mitochondria where exchange with acetyl-L-carnitine occurs (Calvin and Tubbs, 1976). Acetyl-L-carnitine is present in 1000-fold higher concentration than acetyl CoA in bovine and monkey spermatozoa (Casillas and Erickson, 1975), which indicates an important role in buffering acetyl $\mathrm{CoA}$ concentrations. A carnitine acetyltransferase activity should not be a limiting factor, since it is found in testicular spermatozoa (Vernon et al., 1971). High concentration of acetyl-L-carnitine is found inside the mature spermatozoa of boars (Jeulin et al., 1987). However, the exchange between external and internal acetyl-L-carnitine of mature epididymal spermatozoa has not been shown.

Recently, the presence of an acetylcarnitine hydrolase, located on the caudal sperm membrane from hamster and bull, was reported by Bruns and Casillas (1989). Purified plasma membrane vesicles contained an acetyl-L-carnitine hydrolase activity and the detergent-extracted enzyme was purified (Bruns and Casillas, 1990). The role of this enzyme in the exchanges of free L-carnitine by spermatozoa and external media must be considered.

In the present study, we have investigated (1) the pattern of transport of the two compounds free L-carnitine and acetyl-Lcarnitine through the sperm membrane: passive diffusion or active transport process, (2) the influence of epididymal maturation on the mechanisms of free L-carnitine accumulation inside the spermatozoa, (3) the locations and the rates of acetylation of free L-carnitine and de-acetylation of acetyl-Lcarnitine by this specialized cell.

\section{Materials and Methods}

\section{Materials}

L-[Methyl ${ }^{3} \mathrm{H}$ ]carnitine hydrochloride $\left(2.63 \mathrm{TBq} \mathrm{mmol}^{-1}\right.$ ) was purchased from Amersham (Les Wlis); L-carnitine (inner salt from equine muscle) was obtained from Sigma (St Louis, MO) and acetyl-L-carnitine chloride was a gift from Sigma-Tau (Paris); 5,5' dithio-bis-2-nitrobenzoic acid (DTNB) was from Calbiochem (San Diego, CA); acetyl-coenzyme A, coenzyme A,
NAD, carnitine acetyltransferase, malate dehydrogenase and citrate synthase were from Boehringer (Mannheim).

\section{Epididymal plasma and sperm samples}

The epididymal fluid was collected from caput (regions 1 to 4), corpus (regions 5 to 7) and cauda (regions 8 and 9) of the epididymides from Large White boars aged 180 days using the micropuncture technique described by Dacheux et al. (1989). Each region was flushed with $0.2 \mathrm{ml}$ Krebs-Ringerbicarbonate (KRB) solution: $94.6 \mathrm{mmol} \mathrm{NaCl} \mathrm{l}^{-1}, 25 \mathrm{mmol}$ $\mathrm{Na}_{2} \mathrm{CO}_{3} 1^{-1}, 9.6 \mathrm{mmol} \mathrm{KCl} \mathrm{l^{-1 }}, 1.19 \mathrm{mmol} \mathrm{KH}_{2} \mathrm{PO}_{4} 1^{-1}$, $1.7 \mathrm{mmol} \mathrm{CaCl}_{2} \mathrm{l}^{-1}, 1.19 \mathrm{mmol} \mathrm{MgSO}_{4} 1^{-1}, 2 \mathrm{mmol}$ sodium lactate $1^{-1}, 5 \mathrm{mmol}$ glucose $1^{-1}, 0.45 \mathrm{mmol}$ sodium pyruvate $1^{-1}, 10 \mathrm{mmol}$ Hepes $1^{-1}, \mathrm{pH} 8$, osmolarity 310 mosmol $\mathrm{kg}^{-1}$ adjusted with choline chloride. The samples were centrifuged at $650 \mathrm{~g}$ for $10 \mathrm{~min}$, and the supernatant was recentrifuged at $10000 \mathrm{~g}$ for $10 \mathrm{~min}$ (ambient temperature) before storage at $-20^{\circ} \mathrm{C}$.

The epididymal spermatozoa were used after three washes by dilution in $9 \mathrm{ml} \mathrm{KRB}$ solution followed by centrifugation $(500 \mathrm{~g}$ for $15 \mathrm{~min})$. The final concentration of spermatozoa in the different experiments was approximately $10^{9}$ spermatozoa $\mathrm{ml}^{-1}$. The sperm motility of each sample was observed before each experiment to control the sperm quality. After incubation at $32^{\circ} \mathrm{C}$ for an appropriate time (see experiments), three aliquots (50 or $100 \mu \mathrm{l}$ ) of each sample were centrifuged (10 $000 \mathrm{~g}$ for $2 \mathrm{~min}$ ) over $1 \mathrm{ml} \mathrm{KRB-30 \%} \mathrm{Percoll} \mathrm{(Eppendorf}$ tube, Hamburg) and the sperm membrane was then permeabilized in $350 \mu \mathrm{l}$ KRB $-0.2 \%$ Triton $\mathrm{X}-100$ before storage at $-20^{\circ} \mathrm{C}$. Spermatozoa were counted using a haemocytometer and sperm motility score was measured before extraction of free L-carnitine and acetyl-L-carnitine.

\section{Determination of free L-carnitine and acetyl-L-carnitine}

Nine epididymides were used to determine the extracellular and intracellular concentrations of L-carnitine and acetyl-Lcarnitine. The epididymal plasma and sperm samples were homogenized, deproteinized by boiling for $3 \mathrm{~min}$ in KRB $0.2 \%$ Triton $\mathrm{X}-100, \mathrm{pH} 8$ and centrifuged at $12000 \mathrm{~g}$ for $10 \mathrm{~min}$. Free L-carnitine and acetyl-L-carnitine determinations were made by spectrophotometric methods that are specific for each compound (Marquis and Fritz, 1964, 1965) and are described in detail by Jeulin et al. (1987). Results for free $\mathrm{L}$-carnitine and acetyl-L-carnitine concentrations were expressed per $10^{8}$ spermatozoa and $\mathrm{mg}^{-1}$ protein in caput and corpus epididymal plasma (diluted with KRB solution) or $\mathrm{ml}^{-1}$ in plasma of the cauda region (not diluted).

Cytoplasmic location of free L-carnitine and acetyl-Lcarnitine in spermatozoa was estimated after plasma membrane permeabilization with saponin $\left(100 \mu \mathrm{g} \mathrm{ml}^{-1}\right.$ for 2-20 min; Waltz and Baumann, 1989).

\section{Accumulation of free L-carnitine and acetyl-L-carnitine inside spermatozoa}

Time course. The caput spermatozoa were incubated in KRB solution containing non-radioactive free L-carnitine 
Table 1. Free L-carnitine and acetyl-L-carnitine concentrations in boar epididymal plasma and spermatozoa from caput and cauda regions

\section{Caput}

Cauda

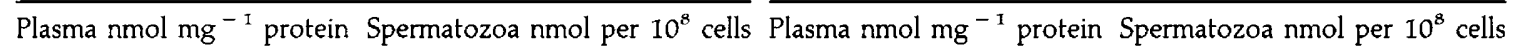

$\begin{array}{lcccc}\text { Free-L-carnitine } & 10.3 \pm 2.5 & 7.3 \pm 1.1 & 556.5 \pm 93.0^{*} & (15) \\ & & (3) & 54.6 \pm 3.8^{*} & (22) \\ \text { Acetyl-L-carnitine } & 6.5 \pm 2.0 & 8.4 \pm 1.6 & 9.2 \pm 1.8 & 44.2 \pm 10.8^{*} \\ & & (3) & (0.2) & (18)\end{array}$

Results are expressed as mean values \pm SEM from 9 experiments.

Numbers in parentheses indicated the mean value of concentrations ( $m m o l 1^{-1}$ ) which were measured in the plasma or calculated by reference to the aqueous volume of the spermatozoa (Hammerstedt et al., 1979). Concentrations are not given for caput plasma samples that were diluted with KRB medium.

${ }^{*} P<0.01$ compared to caput value (Kruskall-Wallis non-parametric test).

$\left(50 \mathrm{mmol} \mathrm{l}^{-1}\right)$ for $2-35 \mathrm{~min}$. Free L-carnitine and acetyl-Lcarnitine determinations were performed on sperm samples. Results are expressed as nmol per $10^{8}$ spermatozoa (triplicate samples).

Radioactive carnitine was used to investigate the uptake of total L-carnitine (free L-carnitine, acetyl-L-carnitine, acyl-Lcarnitine) in spermatozoa. The spermatozoa from caput, corpus and cauda regions of six epididymides were incubated in KRB containing $2.5 \mathrm{mmol}$ non-radioactive free $\mathrm{L}$-carnitine $\mathrm{l}^{-1}$ and $3.7 \times 10^{-3} \mathrm{MBq}$ L-methyl $\left[{ }^{3} \mathrm{H}\right]$ carnitine hydrochloride $\mathrm{ml}^{-1}$ for 2-15 min. The sperm aliquots $(3 \times 100 \mu \mathrm{l})$ were layered on $1 \mathrm{ml}$ silicone oil (Rhodorsil) in hexane (oil/hexane, $10 \mathrm{~g} \mathrm{ml}^{-1}$, Eppendorf tube, Hamburg) and centrifuged (at $10000 \mathrm{~g}$ for $2 \mathrm{~min}$ ). The sperm pellets were dissolved in $1 \mathrm{~mol} \mathrm{NaOH} \mathrm{I}{ }^{-1}$, sonicated, boiled for $5 \mathrm{~min}$ and neutralized before radioactivity was determined. Results are expressed as d.p.m. of $\left[{ }^{3} \mathrm{H}\right]$ carnitine (total carnitine) per $10^{6}$ spermatozoa.

Influence of different exogenous concentrations of free L-carnitine and acetyl-L-carnitine. The caput and cauda spermatozoa (triplicate samples) were incubated in KRB solution containing $37 \times 10^{-3} \mathrm{MBq}\left[{ }^{3} \mathrm{H}\right]$ carnitine $\mathrm{ml}^{-1}$ and $0.002,0.02,0.2$, $2 \mathrm{mmol}$ nonradioactive free L-carnitine $\mathrm{ml}^{-1}$. Uptake was studied after 10 and $20 \mathrm{~min}$. Results are expressed in nmol $\left[{ }^{3} \mathrm{H}\right]$ carnitine (total carnitine) per $10^{8}$ spermatozoa.

A study of higher external concentrations of non-radioactive free L-carnitine and acetyl-L-carnitine $(3.15,6.25,12.5,25$, $50 \mathrm{mmol} \mathrm{I}^{-1}$ ) was performed on caput and cauda spermatozoa incubated for 20 and $30 \mathrm{~min}$, respectively, in KRB solution in the absence of radioactive $\mathrm{L}$-carnitine. Free L-carnitine and acetyl-L-carnitine determinations were performed on sperm samples and results are expressed in nmol per $10^{8}$ spermatozoa.

\section{Free L-carnitine and acetyl-L-carnitine release}

The release of $\left[{ }^{3} \mathrm{H}\right]$ carnitine from caput, corpus and cauda spermatozoa was determined by sixfold dilution in KRB for 15 and $35 \mathrm{~min}$, after uptake $\left(3.7 \times 10^{-3} \mathrm{MBq}\left[{ }^{3} \mathrm{H}\right]\right.$ carnitine $\mathrm{ml}^{-1}$ and $2.5 \mathrm{mmol}$ nonradioactive free L-carnitine $\mathrm{l}^{-1}$ ) for $15 \mathrm{~min}$ (see uptake experiments above). Results were expressed as d.p.m. $\left[{ }^{3} \mathrm{H}\right]$ carnitine per $10^{6}$ spermatozoa.
The release of free L-carnitine and acetyl-L-carnitine was investigated from the free L-camitine and acetyl-L-camitine contents of spermatozoa (triplicate samples). The cauda spermatozoa (approximately $10^{9}$ spermatozoa $\mathrm{ml}^{-1}$ ) were washed three times (in $9 \mathrm{ml} \mathrm{KRB}$ solution and centrifuged at $500 \mathrm{~g}$ for $15 \mathrm{~min}$ ) and then incubated for $75 \mathrm{~min}$ in the same medium. Free L-carnitine and acetyl-L-carnitine determinations were performed in sperm samples after each washing and after incubation.

\section{Hydrolysis of acetyl-L-carnitine in presence of intact epididymal spermatozoa}

Acetyl-L-carnitine hydrolase activity was estimated in sperm suspensions (triplicate samples). The caput or cauda sperm samples were incubated in KRB containing $6.25 \mathrm{mmol}$ acetylL-carnitine $\mathrm{l}^{-1}$ for $10,20,30$ and $100 \mathrm{~min}$ or $0.8,1.75,3.15$, $6.25,12.5 \mathrm{mmol}$ acetyl-L-carnitine $\mathrm{I}^{-1}$ for $30 \mathrm{~min}$. External free L-carnitine and acetyl-L-carnitine were measured in the supernatants after centrifugation $(600 \mathrm{~g}$ for $10 \mathrm{~min})$. Results were expressed in $\mathrm{mmol} \mathrm{l}^{-1}$.

\section{Results}

Determination of the uptake of external free L-carnitine by epididymal spermatozoa in vitro

Concentration of free L-carnitine and acetyl-L-carnitine in collected epididymal plasma and spermatozoa. In epididymal plasma (Table 1), the mean values of the free L-carnitine concentrations showed a 50-fold increase between the caput and caudal regions, while the acetyl-L-carnitine concentrations were not changed in either plasma. The mean value of the acetyl-Lcarnitine : free L-carnitine ratio was lower in the cauda (2\%) compared with the caput $(60 \%)$ region. In epididymal spermatozoa (Table 1), a sixfold increase of the two compounds was observed between the caput and cauda regions. The mean value of the acetyl-L-carnitine: free L-carnitine ratio was not changed inside these spermatozoa (approximately 1:1). The concentration of free L-carnitine in cauda spermatozoa was in the same range outside $\left(15 \mathrm{mmol} \mathrm{l}{ }^{-1}\right)$ and inside $(22 \mathrm{mmol}$ $\mathrm{I}^{-1}$ ) the cells and the intracellular concentration of acetyl-L- 


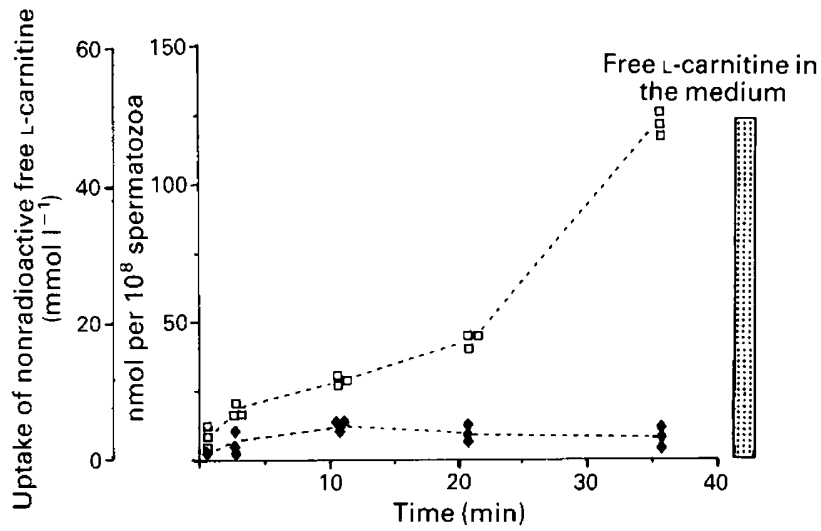

Fig. 1. Uptake of nonradioactive free l-carnitine $\left(50 \mathrm{mmol} \mathrm{l}^{-1}\right.$ ) in vitro by caput epididymal spermatozoa $\left(420 \times 10^{6}\right.$ spermatozoa $\left.\mathrm{ml}^{-1}\right)$ as function of time (2-35 min, triplicate samples). Contents of ( $\square$ ) free L-carnitine and ( $\checkmark$ ) acetyl-L-carnitine in spermatozoa. Results were expressed as nmol per $10^{8}$ spermatozoa. Estimated concentrations of the two compounds in $\mathrm{mmol} \mathrm{l}^{-1}$ are also indicated: these were calculated by reference to the estimated aqueous volume of boar spermatozoa $\left(10^{8}\right.$ cells approximately equal to $2.5 \mu \mathrm{l}$, Hammerstedt et al., 1979). Concentration of free -carnitine in the medium $\left(50 \mathrm{mmol} \mathrm{l}^{-1}\right)$ is also shown.

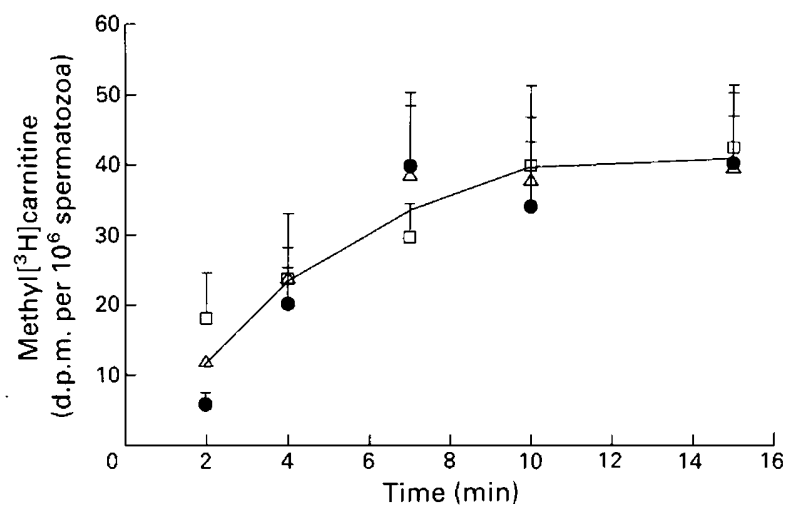

Fig. 2. Uptake of $\mathrm{L}-\left[\right.$ methyl $\left.{ }^{3} \mathrm{H}\right]$ carnitine in vitro by $(\square)$ caput, $(\nabla)$ corpus and $\left(-\right.$ ) cauda epididymal spermatozoa incubated at $32^{\circ} \mathrm{C}$ for $15 \mathrm{~min}$ in Krebs-Ringer-bicarbonate solution containing $2.5 \mathrm{mmol}$ nonradioactive free $L$-carnitine $!^{-1}$. Results were expressed as d.p.m. $\left[{ }^{3} \mathrm{H}\right]$ carnitine (total carnitine) per $10^{6}$ spermatozoa (mean values \pm SEM of six experiments).

carnitine was much higher (approximately 90 times greater) than its extracellular concentration.

Uptake of external free L-carnitine in vitro. When immature spermatozoa (caput) that contained low concentrations of intracellular free L-carnitine in vivo were incubated in the presence of $50 \mathrm{mmol}$ free-L-carnitine $\mathrm{I}^{-1}$, the intracellular concentration of free L-carnitine increased (Fig. 1). After incubation for $35 \mathrm{~min}$, an equilibrium between intracellular and extracellular concentrations was reached. However, the intracellular concentration of acetyl-L-carnitine of immature spermatozoa remained low whatever the incubation time (Fig. 1). When $\mathrm{L}$-[methyl ${ }^{3} \mathrm{H}$ ]carnitine associated with $2.5 \mathrm{mmol}$ nonradioactive free L-carnitine $l^{-1}$ was used to study the influx of

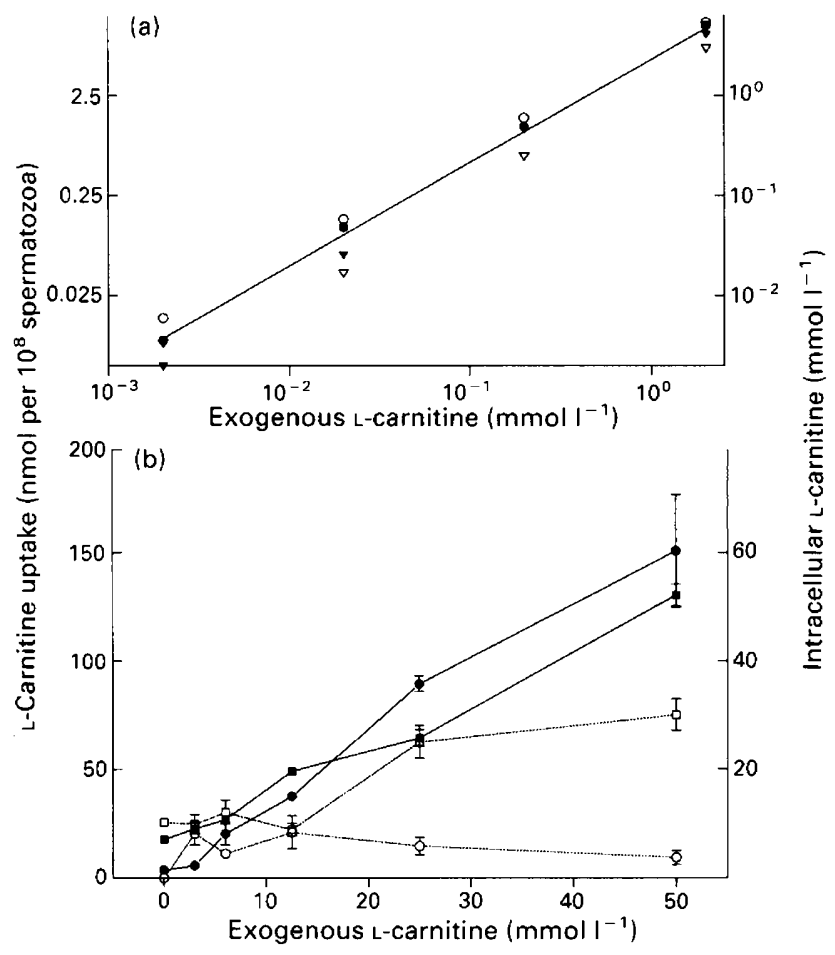

Fig. 3. (a) L-[methyl $\left.{ }^{3} \mathrm{H}\right]$ carnitine (total carnitine) uptake (nmol per $10^{8}$ spermatozoa, mean values, triplicate samples, one experiment) as a function of free L-carnitine concentrations $\left(0.002-2 \mathrm{mmol} \mathrm{l}^{-1}\right)$ at 10 (open symbols) and $20 \mathrm{~min}$ (closed symbols) incubation, $(O)$ caput and $(\nabla)$ cauda. Total carnitine uptake was not different whatever the origin of the spermatozoa. Results are expressed as nmol total carnitine per $10^{\mathrm{B}}$ spermatozoa. (b) Uptake of nonradioactive free L-carnitine $\left(3-50 \mathrm{mmol} \mathrm{l}^{-1}\right)$ in vitro by caput $\left(0,0,125 \times 10^{6}\right.$ spermatozoa $\mathrm{ml}^{-1}$ ) and cauda ( $\square, \mathbf{\square}, 148 \times 10^{6}$ spermatozoa $\mathrm{ml}^{-1}$ ) spermatozoa for $20 \mathrm{~min}$. Closed and open symbols are sperm free L-carnitine and acetyl-L-carnitine contents, respectively. Results are expressed as nmol free L-carnitine and acetyl-L-carnitine per $10^{8}$ spermatozoa. The intracellular concentrations $\left(\mathrm{mmol} \mathrm{l}^{-1}\right)$ of the two compounds were calculated also.

this compound through the sperm plasma membrane after incubation for $15 \mathrm{~min}$, the amount of radioactivity in the total carnitine inside spermatozoa rose to equilibrium. No difference was found between the kinetics whatever the stage of maturation of the spermatozoa collected in the caput, corpus and cauda epididymides (Fig. 2). All the sperm suspensions were preincubated in a carnitine-free KRB medium for approximately I h (this method was chosen before the result obtained below) and consequently an equilibrium between the extracellular and intracellular compartment of the spermatozoa occurred before the flux experiments.

The uptake of total carnitine by immature and mature spermatozoa as a function of external concentration of L-carnitine of $0.002-2 \mathrm{mmol} \mathrm{l}^{-1}$ in the presence of L-[methyl ${ }^{3} \mathrm{H}$ ] carnitine is shown (Fig. 3a). The uptake of $3-50 \mathrm{mmol}$ free L-carnitine $1^{-1}$ could not be studied with labelled carnitine because these tested concentrations were very high (Fig. 3b). Accumulation of total or free L-carnitine inside the spermatozoa was linearly correlated with the external concentration of free L-carnitine. Similar rates of uptake were observed whatever the 
Table 2. Sperm free-L-carnitine and acetyl-L-carnitine contents (nmol per $10^{8}$ spermatozoa) of caput spermatozoa incubated for $30 \mathrm{~min}$ in a medium containing increasing concentrations of acetyl-L-carnitine

\begin{tabular}{lccccc}
\hline & \multicolumn{5}{c}{ Exogenous acetyl-L-carnitine $\left(\mathrm{mmol} \mathrm{I}^{-1}\right)$} \\
\cline { 2 - 6 } & 0 & 3.12 & 6.25 & 12.5 & 25 \\
\hline Free L-carnitine & $4.7 \pm 2.5$ & $5.4 \pm 2.4$ & $5.2 \pm 1.4$ & $6.0 \pm 2.3$ & $5.6 \pm 1.0$ \\
Acetyl-L-carnitine & $6.2 \pm 5.6$ & $5.0 \pm 4.5$ & $18.4 \pm 16.0$ & $28.0 \pm 14.8$ & $\begin{array}{c}47.4 \pm 12.7 \\
(18.9)\end{array}$ \\
\hline
\end{tabular}

Mean values \pm SD from 3 experiments, triplicate samples.

Number in parentheses indicates the concentration $\left(\mathrm{mmol} \mathrm{l}^{-\mathrm{I}}\right)$ which was calculated by reference to the aqueous volume of the boar spermatozoa (Hammerstedt et al., 1979).

epididymal origin of the spermatozoa. However, the intracellular concentration of acetyl-L-carnitine remained very low in immature spermatozoa, in spite of the accumulation of free L-carnitine, whereas the accumulation of free L-carnitine in cauda spermatozoa was paralleled by an increase in intracellular concentration of acetyl L-carnitine (Fig. 3b). The intracellular acetyl-L-carnitine:free L-carnitine ratio of the cauda spermatozoa was approximately (1:1), whatever the external concentration of free L-carnitine.

Determination of the uptake of external acetyl-L-carnitine by epididymal spermatozoa in vitro

The caput spermatozoa, which contained very low amounts of acetyl-L-carnitine in vivo were incubated for $30 \mathrm{~min}$ in a medium containing increasing concentrations of acetyl-Lcarnitine $\left(3-25 \mathrm{mmol} \mathrm{l}^{-1}\right)$. The acetyl-L-carnitine content of these caput spermatozoa increased linearly in relation to the external concentration of the compound (Table 2). In the presence of $25 \mathrm{mmol}$ acetyl-L-carnitine $\mathrm{l}^{-1}$, an estimated concentration of $18.9 \mathrm{mmol} \mathrm{I}^{-1}$ was found inside the spermatozoa. The concentration of free L-carnitine remained low, whatever the intracellular concentration of acetyl-L-carnitine.

\section{Intracellular free L-carnitine and acetyl-L-carnitine in spermatozoa incubated in a carnitine-free KRB medium}

A change in the total carnitine concentration inside the spermatozoa was observed on gametes previously incubated for $15 \mathrm{~min}$ with $\mathrm{L}$-[methyl $\left.{ }^{3} \mathrm{H}\right]$ carnitine and $2.5 \mathrm{mmol}$ nonradioactive carnitine $1^{-1}$ and then diluted sixfold in a carnitinefree KRB medium. The $\left[{ }^{3} \mathrm{H}\right]$ carnitine content (total carnitine) decreased to $80 \%$ in approximately $15 \mathrm{~min}$ after dilution of the sperm suspensions, whatever the origin of the spermatozoa (caput, corpus and cauda, Fig. 4a). The concentrations of free $\mathrm{L}$-carnitine and acetyl-L-carnitine inside the spermatozoa were also estimated after washing followed by preincubation of the gametes for $30 \mathrm{~min}$ in carnitine-free medium. These treatments applied on cauda spermatozoa showed a significant decrease of the sperm free L-carnitine (38\%) and acetyl-L-carnitine (50\%) contents at the end of the incubation $(75 \mathrm{~min}$, Fig. 4b); however, mean percentage sperm motility was maintained in the range $60-70 \%$.
Table 3. Hydrolysis of acetyl-L-carnitine $\left(6.25 \mathrm{mmol} \mathrm{l}^{-1}\right)$ by intact caput $\left(42 \times 10^{6}\right.$ spermatozoa ml $\left.{ }^{-1}\right)$ and cauda $\left(86 \times 10^{6}\right.$ spermatozoa $\mathrm{ml}^{-1}$ ) boar spermatozoa as determined by measurement of free L-carnitine accumulation in the medium and as a function of time

\begin{tabular}{lcc}
\hline & \multicolumn{2}{c}{ Free L-carnitine $\left(\mathrm{mmol} \mathrm{l}^{-1}\right)$} \\
\cline { 2 - 3 } Incubation time (min) & Caput spermatozoa & Cauda spermatozoa \\
\hline & & \\
10 & 0.10 & 0.12 \\
20 & 0.23 & 0.16 \\
30 & 0.10 & 0.16 \\
\hline
\end{tabular}

Mean value, from one experiment, triplicate samples.

$6.25 \mathrm{mmol} \mathrm{l}^{-1}$ acetyl-L-carnitine (Sigma-Tau) in KRB solution contained $0.01 \mathrm{mmol}$ free L-carnitine $\mathrm{l}^{-1}$.

Intracellular location of free L-carnitine and acetyl-L-carnitine inside the spermatozoa

After permeabilization of the sperm membrane by saponin, both free L-carnitine and acetyl-L-carnitine contents of cauda spermatozoa decreased after incubation for $2 \mathrm{~min}$ (carnitine: 15 versus $46 \mathrm{nmol}$ per $10^{8}$ spermatozoa; acetylcarnitine: 2 versus $35 \mathrm{nmol}$ per $10^{8}$ spermatozoa). The concentration of saponin used $\left(100 \mu \mathrm{g} \mathrm{ml}^{-1}\right)$ is reported to leave the mitochondrial membranes intact. The mitochondrial compartment may therefore contain $33 \%$ of the initial sperm free L-carnitine content and $6 \%$ of the acetyl-L-carnitine content. Similar results were obtained after incubation with saponin for $18 \mathrm{~min}$.

\section{Hydrolysis of acetyl-L-carnitine in the sperm incubation medium}

After incubation of the sperm suspensions with $6.25 \mathrm{mmol}$ acetyl-L-carnitine $\mathrm{l}^{-1}$, free $\mathrm{L}$-carnitine was present in the medium in the presence of mature and immature spermatozoa (Table 3). However, the amount of free L-carnitine produced in vitro reached a plateau after incubation for $20 \mathrm{~min}$.

When increasing concentrations of acetyl-L-carnitine were incubated for $30 \mathrm{~min}$ with cauda spermatozoa, there was a linear relationship between free L-carnitine produced in the medium and exogenous acetyl-L-carnitine added in the range 


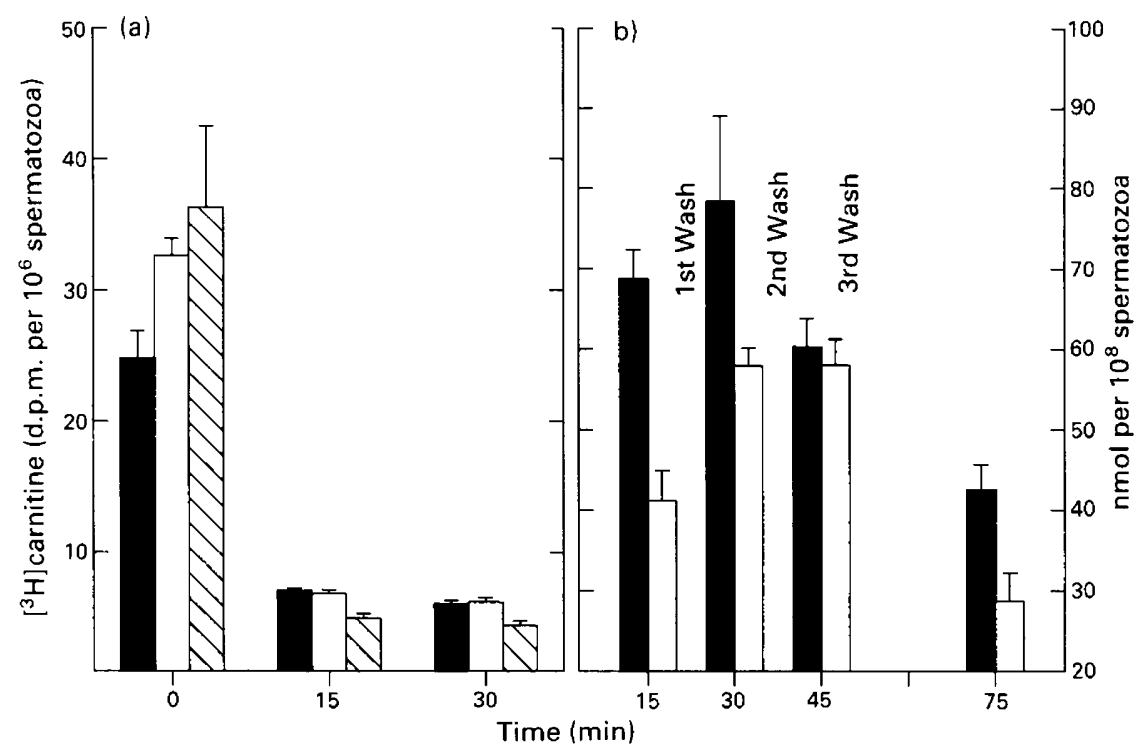

Fig. 4. (a) Release of L-[methyl ${ }^{3} \mathrm{H}$ ]carnitine from ( $\mathbf{\square}$ ) caput, ( $\square$ ) corpus and ( $\nabla$ ) cauda spermatozoa first charged for $15 \mathrm{~min}$ with $\left[{ }^{3} \mathrm{H}\right]$ carnitine and $2.5 \mathrm{mmol} 1^{-1}$ nonradioactive free-L-carnitine and then diluted sixfold (triplicate samples, mean values). (b) Release of nonradioactive ( $\boldsymbol{\square})$ intracellular free L-carnitine and $(\square)$ intracellular acetyl-L-carnitine from cauda spermatozoa $\left(148 \times 10^{6}\right.$ spermatozoa $\left.\mathrm{ml}^{-1}\right)$ which were washed $(\times 3)$ and incubated (75 $\mathrm{min})$ in carnitine-free-Krebs-Ringer-bicarbonate solution.

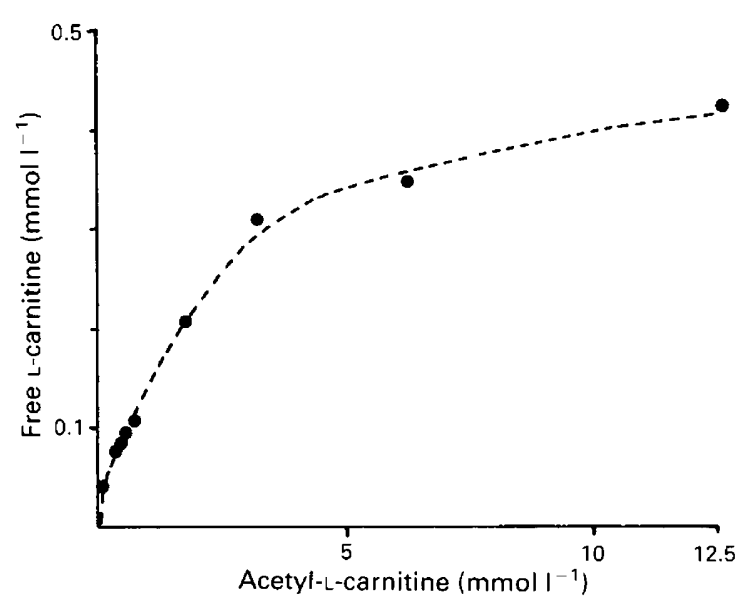

Fig. 5. Hydrolysis of exogenous acetyl-L-camitine by sperm plasma membranes. Cauda spermatozoa $\left(88 \times 10^{6}\right.$ spermatozoa $\left.\mathrm{ml}^{-1}\right)$ were incubated with increasing concentrations of acetyl-L-carnitine $(0.0025-$ $12.5 \mathrm{mmol} \mathrm{I}^{-1}$, Sigma-Tau, containing less than $0.2 \%$ free L-carnitine) for $30 \mathrm{~min}$. Results were mean values for triplicate samples.

$0.0025-3.15 \mathrm{mmol}^{-1}$. Above such concentrations (3.15$12.5 \mathrm{mmol} \mathrm{I}^{-1}$ ) the free L-carnitine concentration approached a plateau (Fig. 5).

\section{Discussion}

Results from the study reported here clarify the mechanism of transport of free L-carnitine and acetyl-L-carnitine across the sperm plasma membrane.
Millimolar concentrations of free L-carnitine were used because these concentrations are found in the epididymal plasma of many species.

The linear relationship between intracellular and extracellular concentrations of free L-carnitine suggests that the transport of this compound (at the concentration of the order of $\mathrm{mmol} \mathrm{l}^{-1}$ ) into the caput, corpus and cauda spermatozoa occurred by a passive mechanism. In the presence of $2.5 \mathrm{mmol}$ free L-carnitine $\mathrm{I}^{-1}$ in the medium, the equilibrium between extracellular and intracellular compartments was reached after $10-15 \mathrm{~min}$, while a longer time $(20-35 \mathrm{~min})$ was required in a medium containing concentrations of up to $50 \mathrm{mmol} \mathrm{l}^{-1}$. The diffusion of large amounts of free L-carnitine through the sperm plasma membrane takes about $30 \mathrm{~min}$. The internal concentration of free L-camitine in caput and cauda spermatozoa is in equilibrium with the external medium containing free L-carnitine after incubation for $30 \mathrm{~min}$. When micromolar concentrations of free L-carnitine were used in the incubation, the internal concentration of total carnitine, which was estimated by calculation, was also never higher than the external concentration.

Exogenous acetyl-L-carnitine (3-25 $\mathrm{mmol} \mathrm{l}^{-1}$ ) also entered the caput spermatozoa (containing low amounts of acetyl-Lcarnitine in vivo) by passive diffusion, since $18.9 \mathrm{mmol} \mathrm{l}^{-1}$ was found inside the spermatozoa when $25 \mathrm{mmol}$ acetyl-L-carnitine $1^{-1}$ was added to the external medium.

Uptake of free L-carnitine and acetyl-L-carnitine by somatic cells has been studied in vivo, in isolated organs and in cultured cells. The uptake of carnitine into tissues is of considerable importance as impaired active uptake into tissue such as muscle contributes to 'human carnitine deficiency' disease (Engel, 1980; Scholte ef al., 1990). Recent results have helped to 
explain conflicting findings from studies of passive and active transport of carnitine. At pharmacological concentrations (mmol 1-I), free L-carnitine accumulates slowly by simple diffusion in the small intestine of rats (Marciani et al., 1991) in human jejunum ( $\mathrm{Li}$ et al., 1990, 1992) and in human skin fibroblasts and cultured muscle biopsy (Tein et al., 1990; Martinuzzi et al., 1991). Physiological concentrations $\left(\mu \mathrm{mol} \mathrm{l^{-1 }}\right)$ of $\mathrm{L}$-carnitine cross the membrane of these cells by an active transport system via anion-dependent carrier (findings reported in the same references). There are two mechanisms of uptake of carnitine, a specific saturable carriermediated active transport and an intracellular accumulation by simple diffusion. In boar spermatozoa, simple diffusion of free L-carnitine only occurs. There is no effect of the epididymal maturation on the sperm free L-carnitine uptake, as the caput and corpus spermatozoa accumulate the compound as do caudal epididymal spermatozoa. These results confirm those reported by Casillas (1973) in bovine caput epididymal spermatozoa, but not those obtained with caudal cells. Differences between the experiments of Casillas and co-workers and the experiments reported here are that our sperm samples were always washed and incubated in a carnitine-free medium for approximately $1 \mathrm{~h}$ before accumulation of free $\mathrm{L}$-carnitine and acetyl-L-carnitine in vitro. High exogenous concentrations of up to 25 or $50 \mathrm{mmol} \mathrm{I}^{-1}$ were used. The passive accumulation of free L-carnitine into the cauda spermatozoa occurs only when the external concentration of the compound is higher than its internal concentration. Deana et al. (1989) also reported that carnitine was rapidly taken up (5-10 $\mathrm{min}$ ) by ejaculated bovine spermatozoa and showed that the rate of uptake was strongly dependent on temperature and extracellular concentration of carnitine in the range of $1-20 \mathrm{mmol} \mathrm{l}^{-1}$.

The study reported here shows that effluxes of free L-carnitine and its ester in vitro into the surrounding medium occur, whatever the stage of sperm maturation. The results reported here suggest that free L-carnitine and acetyl-L-carnitine are distributed in cytoplasmic and mitochondrial compartments where minimal intracellular concentrations of both compounds are maintained. The saponin experiment supported this hypothesis and showed that $67 \%$ of free L-carnitine and $94 \%$ of acetyl-L-carnitine were located in the cytoplasm. When the effects of saponin and washing plus incubation were compared, the mitochondrial compartment was found to contain $50-60 \%$ of the cellular free L-carnitine and only $5-10 \%$ of acetyl-Lcarnitine. The effluxes of free L-carnitine and acetyl-L-carnitine during sperm preparation might explain previous findings which showed that carnitine accumulates in boar epididymal plasma faster than in spermatozoa (Jeulin et al., 1987, 1988). This time lag might result from an underestimation of the intracellular concentrations measured in the sperm samples collected, particularly when intracellular concentrations of free L-carnitine in spermatozoa were low or moderate.

In the study reported here a lack of balance was found in the acetyl-L-carnitine concentrations outside and inside the mature boar spermatozoa. A low external acetyl-L-carnitine concentration $\left(0.2 \mathrm{mmol}^{-1}\right.$ in cauda plasma and $0 \mathrm{mmol} \mathrm{l}^{-1}$ in KRB medium) was consistent with a high intracellular concentration $\left(15-20 \mathrm{mmol} \mathrm{l}^{-1}\right)$ in cauda spermatozoa. We suggest that acetyl $\mathrm{L}$-carnitine inside the mature spermatozoa has a diffusion rate through the lipid component of the inner face of the sperm membrane that is slower than the rate of acetylation of the free L-carnitine inside the spermatozoa. If this is the case, equilibrium should not be reached. A high intracellular acetyl-Lcarnitine concentration might be also explained by formation of acetyl CoA produced by an increase in the oxidative metabolism of spermatozoa from the caput to the cauda regions (in rats: Brooks, 1979a; and in boars: Dacheux and Paquignon, 1980). This accumulation of acetyl groups by spermatozoa seems to occur in parallel with the increasing concentrations of free L-carnitine, which acts as a buffer for excess acetyl $\mathrm{CoA}$, as occurs in muscle during exercise (Constantin-Teodosiu et al., 1991). The ratio of acetyl-Lcarnitine: free L-carnitine of these mature spermatozoa was estimated as 1:1 (up to $50 \mathrm{mmol} \mathrm{l}^{-1}$ ). In caput spermatozoa, the low acetylation of free L-carnitine might parallel a low oxidative metabolism (low acetyl CoA production or low amount of coenzyme A). Those caput spermatozoa that had a high intracellular acetyl L-carnitine content showed very rapid flagellar beats (Jeulin and Soufir, 1992).

We also clearly showed that the diffusion of large amounts of free L-carnitine into immature caput spermatozoa was never accompanied by an increase of acetyl-L-carnitine content. This finding may be attributed to (i) low carnitine acetyltransferase activity, (ii) low production of acetyl groups or (iii) low concentration of intracellular coenzyme $\mathrm{A}$. It is possible that there is a homeostatic equilibrium between free L-carnitine and acetyl-L-carnitine in the spermatozoa which is maintained by the activity of carnitine acetyltransferase and related to the concentration of coenzyme $\mathrm{A}$ and acetyl $\mathrm{CoA}$.

The difference between the concentration of acetyl-Lcarnitine outside and inside the mature spermatozoa might also be explained by hydrolysis of acetyl-L-carnitine in the external medium. Bruns and Casillas (1989, 1990) explained that acetyl$\mathrm{L}$-carnitine is hydrolysed by an acetylcarnitine hydrolase located on the sperm surface producing an acetate moiety which may enter the mature cell to be used for their metabolism. In this study on boar spermatozoa, we observed that exogenous acetyl-L-carnitine enters caput spermatozoa by passive diffusion without a high rate of hydrolysis of the compound. Approximately $3 \%$ of the acetyl-L-carnitine added to the medium was hydrolysed to carnitine in $20 \mathrm{~min}$ by caput and cauda cells. Enzymatic activity, if present, is low in the boar spermatozoa.

Some cellular functions are related to the accumulation of these substances in spermatozoa. Acetyl-L-carnitine may be consumed when spermatozoa undergo a burst of motility or respiratory activity (perhaps in fluids of the female tract). This effect was demonstrated in vitro on bovine epididymal spermatozoa (Milkowski et al., 1976). Smith et al. (1985) suggested that acetyl-L-carnitine may be used to replace the energy storage function of phosphagens in mammalian spermatozoa. In boar, ram, goat and bull spermatozoa there are no high energy molecules such as phosphoarginine or phosphocreatine which could act as energy transfer substances (Robitaille et al., 1987). The pool of acetyl-L-carnitine in spermatozoa might serve as a readily accessible energy store. Two observations support this hypothesis, (i) acetyl-L-carnitine, $0.3-30 \mathrm{mmol} \mathrm{l}^{-1}$, stimulates both the percentage of human sperm motility and their velocity in vitro (Jeulin et al., 1981), (ii) $5 \mathrm{mmol}$ acetyl-L-carnitine $\mathrm{I}^{-1}$ restores the progressive velocity of 
ATP-depleted rat spermatozoa (C. Jeulin, unpublished observation).

In conclusion, our results show clearly that mature spermatozoa in the mammalian cauda epididymides contain high concentrations of free L-carnitine and acetyl-L-carnitine. This results mainly from passive exchange with free L-carnitine of the fluid. There may be at least two sources of acetyl units; the first is mitochondrial oxidative metabolism which increases as the spermatozoa progress in the ductus, and the second is acetyl-L-carnitine present in the fluid which could be hydrolysed to acetate and carnitine by the acetylcarnitine hydrolase activity located on the sperm membrane. This enzyme activity appeared limited in the boar. Intracellular acetyl-L-carnitine may be a metabolic fuel used by the spermatozoa during their short life.

This work was supported by a grant of UFR médicale Kremlin-Bicêtre, Université Paris XI, France, 1989-1990. The authors thank A. Boutron, Laboratorie de Biochimie, CHU, Kremlin-Bicêtre, for his comments and critical reading of the manuscript and $\mathrm{L}$. Lewin, Sackler Medical School, Tel-Aviv University, Israel, for his comments and his help in the English translation.

\section{References}

Bohmer T, Eiklid K and Jonsen J (1977) Carnitine functions Biochimica et Biophysica Acta 471 145-155

Borum PR (1983) Carnitine Annual Review of Nutrition 3 233-259

Bremer J (1983) Carnitine: metabolism and functions Physiological Review 63 $1420-1479$

Brooks DE (1979a) Biochemical environment of sperm maturation. In The Spermatozoon, pp 23-34 Eds DW Fawcett and JM Bedford. Urban and Schwarzenberg Inc, Baltimore-Munich

Brooks DE (1979b) Carnitine, acetylcarnitine and the activity of carnitine acetyltransferases in seminal plasma and spermatozoa of men, rams and rats Journal of Reproduction and Fertility 56 667-673

Brooks DE (1980) Carnitine in the male reproductive tract and its relation to the metabolism of the epididymis and spermatozoa. In Carnitine Biosynthesis, Metabolism and Functions, pp 219-235 Eds RA Frenkel and JD McGarry. Academic Press, New York

Bruns KA and Casillas ER (1989) The metabolism of acetylcarnitine and acetate by bovine and hamster epididymal spermatozoa Biology of Reproduction $\mathbf{4 1}$, 218-226

Bruns KA and Casillas ER (1990) Partial purification and characterization of an acetylcarnitine hydrolase from bovine epididymal spermatozoa Archives of Biochemistry and Biophysics 277 1-7

Calvin J and Tubbs PK (1976) A carnitine: acetylcarnitine exchange system in spermatozoa Journal of Reproduction and Fertility 48 417-420

Casillas ER (1972) The distribution of carnitine in male reproductive tissues and its effect on palmitate oxidation by spermatozoal particles Biochimica ef Biophysica Acta 280 545-551

Casillas ER (1973) Accumulation of carnitine by bovine spermatozoa during maturation in the epididymis Journal of Biological Chemistry 23 8227-8232

Casillas ER and Chaipayungpan S (1979) The distribution of camitine and acetylcarnitine in the rabbit epididymis and the carnitine content of rabbit spermatozoa during maturation Journal of Reproduction and Fertility 56 439-444

Casillas ER and Erickson BJ (1975) The role of carnitine in spermatozoan metabolism: substrate-induced elevations in the acetylation state of carnitine and Coenzyme $A$ in bovine and monkey spermatozoa Biology of Reproduction 12, 275-283

Casillas ER, Villalobos P and Gonzales R (1984) Distribution of carnitine and acetylcamitine in the hamster epididymis and in epididymal spermatozoa during maturation Journal of Reproduction and Fertility 7 197-201

Constantin-Teodosiu D, Carlin II, Cederblad G, Harris RC and Hultman E (1991) Acetyl group accumulation and pyruvate dehydrogenase activity in human muscle during incremental exercise Acta Physiologica Scandinavia 143 $367-372$
Cooper TG, Gudermann TW and Yeung CH (1986a) Characteristics of the transport of carnitine into the cauda epididymis of the rat as ascertained by luminal perfusion in vitro. International Journal of Andrology 9 348-358

Cooper TG, Yeung CH and Weinbauer GF (1986b) Transport of carnitine by the epididymis of the cynomolgus macaque (Macaca fascicularis) Journal of Reproduction and Fertility 77 297-301

Dacheux IL and Paquignon M (1980) Relation between the fertilizing ability, motility and metabolism of epididymal spermatozoa Reproduction Nutrition et Developpement 20 1085-1099

Dacheux JL, Dacheux F and Paquignon M (1989) Changes in sperm surface membrane and luminal protein fluid content during epididymal transit in the boar Biology of Reproduction 40 635-651

Day-Francesconi and Casillas ER (1982) The intracellular localization and properties of carnitine acetyltransferase from ram spermatozoa Archives of Biochemistry and Biophysics 215 206-214

Deana R, Rigoni F, Francesconi M, Cavallini L, Arslan P and Siliprandi N (1989) Effect of L-carnitine and L-aminocarnitine on calcium transport motility and enzyme release from ejaculated bovine spermatozoa Biology of Reproduction 41 949-955

Engel AG (1980) Possible causes and effects of carnitine deficiency in man. In Carnitine Biosynthesis, Metabolism and Functions, pp 271-285 Eds RA Frenkel and JD McGarry, Academic Press, New York

Hammerstedt RH, Keith AD, Hay S, Deluca N and Amann RP (1979) Changes in ram sperm membranes during epididymal transit Archives of Biochemistry and Biophysics $1967-12$

Hinton BT and Setchell BP (1980) Concentration and uptake of carnitine in the rat epididymis: a micropuncture study. In Camitine Biosynthesis, Metabolism and Functions, pp 237-250. Eds RA Frenkel and JD McGarry. Academic Press, New York

Hinton BT, Snoswell AM and Setchell BP (1979) The concentration of carnitine in the luminal fluid of the testis and epididymis of the rat and some other mammals Journal of Reproduction and Fertility 56 105-111

Inskeep PB and Hammerstedt RH (1982) Changes in metabolism for ram sperm associated with epididymal transit or induced by exogenous carnitine Biology of Reproduction 27 735-743

Jeulin C and Soufir JC (1992) Reversible intracellular ATP changes in intact rat spermatozoa and effects on flagellar sperm movement Cell Motility and Cytoskeleton 21 210-222

Jeulin C, Soufir JC and Jouannet P (1981) The effects of L-carnitine and D-L-acetylcarnitine on human sperm motility as measured by laser doppler velocimetry IRCS Medical Science 9 722-723

Jeulin C, Soufir JC, Marson J, Paquignon M and Dacheux JL (1987) The distribution of carnitine and acetylcarnitine in the epididymis and epididymal spermatozoa of the boar Journal of Reproduction and Fertility 79 523-529

Jeulin C, Soufir JC, Marson J, Paquignon M and Dacheux JL (1988) Acétylcarnitine et spermatozoides: relation avec la maturation épididymaire et la mobilité chez le verrat et l'homme Reproduction Nutrition et Développement 28 1317-1328

Li BK, Burmmer PM, Hamilton JW, Gudjonsson H, Zografi G and Olsen WA (1990) Uptake of L-carnitine by rat jejunal brush border microvillous membrane vesicles: evidence of passive diffusion Digestive Diseases and Sciences 35 333-339

Li BK, Lloyd ML, Gudjonsson H, Shug AL and Olsen WA (1992) The effect of enteral carnitine administration in humans. American Journal of Clinical Nutrition 55 838-845

Marciani P, Lindi C, Marzo A, Arrigoni-Martelli E, Cardace G and Esposito G (1991) L-Carnitine and carnitine ester transport in the rat small intestine Pharmacological Research 23 157-162

Marquis NRP and Fritz IB (1964) Enzymological determination of free carnitine concentrations in rat tissues Journal of Lipid Research 5 184-187

Marquis NRP and Fritz IB (1965) The distribution of carnitine, acetylcarnitine and carnitine acetyl transferase in rat tissues Journal of Biological Chemistry $2402193-2197$

Martinuzzi A, Vergani L, Rosa M and Angelini C (1991) L-Carnitine uptake in differentiating human cultured muscle Biochimica et Biophysica Acta 1095 217-222

Milkowski AL, Babcock DF and Lardy HA (1976) Activation of bovine epididymal sperm respiration by caffeine, its transient nature and relationship to the utilization of acetylcarnitine Archives of Biochemistry and Biophysics 176 250-256

Rebouche CJ (1977) Carnitine movement across muscle cell membranes: studies in isolated rat muscle Biochimica et Biophysica Acta 471 145-155 
Robitaille PML, Robitaille PA, Martin PA and Brown GG (1987) Phosphorus-31 nuclear magnetic resonance studies of spermatozoa from the boar, ram, goat and bull Comparative and Biochemical Physiology 87B 285-296

Scholte HR, Pereira RR, De Jouge PC, Liyt-Houwen IEM, Verduin MHM and Ross JD (1990) Primary carnitine deficiency Journal of Clinical Chemistry and Clinical Biochemistry 28 351-357

Smith MB, Babcock DF and Lardy HA (1985) A ${ }^{31} \mathrm{P}$ NMR study of the epididymis and epididymal sperm of the bull and hamster Biology of Reproduction 33 1029-1040

Tein I, De Vivo C, Bierman F, Pulver P, De Meirleir J, Cvitanovic-sojat L, Pagon RA, Bertini E, Dionisi-Vici C, Servidei S and Dimauro S (1990) Impaired skin fibroblast carnitine uptake in primary systemic carnitine deficiency manifested by childhood carnitine-responsive cardiomyopathy Pediatric Research 28 247-255
Van Dop C, Huston SM and Lardy HA (1977) Pyruvate metabolism in bovine epididymal spermatozoa Journal of Biological Chemistry 252 1303-1308

Vernon RG, Go VLW and Fritz IB (1971) Studies on spermatogenesis in rats. II Evidence that acetylcarnitine transferase is a marker enzyme for the investigation of germ cell differentiation Canadian Journal of Biochemistry $\mathbf{4 9}$ 761-769

Waltz B and Baumann O (1989) Calcium-sequestring cell organelles: In situ Localization, morphological and functional characterization. In Progress in histochemistry and cytochemistry, Vol. 20, 2, pp 1-47. Gustav-Fisher, Verlag Stuttgart, New York

Yeung CH, Cooper TG and Waites GMH (1980) Carnitine transport into the perfused epididymis of the rat: regional differences, stereospecificity, stimulation by choline and effects of other luminal compounds Biology of Reproduction 23 294-303 